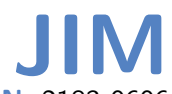

ISSN: 2183-0606

(CC BY 3.0)

Vol. 9, 2 (2021)

p. $64-80$

AM: Jul/2021

SM: Mar/2021

\title{
Digitainability: The Combined Effects of the Megatrends Digitalization and Sustainability
}

\author{
Ulrich Lichtenthaler ${ }^{1}$ \\ ${ }^{1}$ International School of Management (ISM), Im MediaPark 5c, 50670 Cologne, Germany | \\ lichtenthaler@web.de
}

\begin{abstract}
The concept of digitainability has recently been suggested to underscore potential cross-fertilization effects between digitalization and sustainability, which have often been neglected. This conceptual article draws on an innovation-based view to develop a framework for combining digitalization and sustainability in firms' strategic initiatives. It distinguishes four settings depending on whether firms pursue either digitalization or sustainability - or both or none of them to a strong degree. Beyond the individual importance of the two megatrends, their positive and negative interdependencies will gain further importance, and this article underscores the need for overcoming a potential dark side of digital solutions in terms of their carbon footprint and energy consumption to enable a sustainable digital transformation. In addition, digitainability offers the opportunity to move beyond optimization and cost savings due to digitalization and sustainability initiatives in order to capture the cross-fertilization potential of these two megatrends for innovation, business development, and sustainable design.
\end{abstract}

Keywords: Digital Transformation, Digitainability, Digitalization, Innovation-based View, Megatrends, Sustainability, Sustainable Development Goals, Strategic Renewal.

Cite paper as: Lichtenthaler, U.C., (2021). Digitainability: The Combined Effects of the Megatrends Digitalization and Sustainability, Journal of Innovation Management, 9(2), 64-80.; DOI: https://doi.org/10.24840/2183-0606_ 009.002_0006

\section{Introduction}

In reaction to the COVID-19 pandemic, numerous governments worldwide have set up recovery plans and investments initiatives to reduce the negative economic consequences and to help firms and economies recover from the crisis (Carlsson-Szlezak, Reeves, \& Swartz, 2020; Reeves, Lang, \& Carlsson-Szlezak, 2020). For instance, the European Union has set up a recovery plan, which "will be the largest stimulus package ever financed through the EU budget. A total of $€ 1.8$ trillion will help rebuild a post-COVID-19 Europe. It will be a greener, more digital and more resilient Europe" (European-Commission, 2020). Thus, sustainability and digitalization play a key role in the attempt to set the foundations for a future-oriented Europe according to this plan, on which the European Commission, the European Parliament, and the leaders of the member countries have agreed (European-Commission, 2020). This is only one among many examples which illustrate that sustainability and digitalization constitute two essential megatrends, which will play a dominant role in shaping economies and the business activities of companies for years to come (Aksin-Sivrikaya \& Bhattacharya, 2017; del Río Castro, González-Fernández, \& Uruburu-Colsa, 2020).

While the COVID-19 crisis has further strengthened the public attention to sustainability and digitalization, these transformations are not new (Fowler \& Hope, 2007; Lohrmann, 2017; 
Mention, Torkkeli, \& Pinto-Ferreira, 2020). However, there is a renewed interest in sustainability in the context of a growing world population and increasing environmental problems (Keller \& Bette, 2020; Mühlbacher \& Böbel, 2019). Enabling the current level of consumption of developed economies for all people worldwide will be impossible at the present level of resource utilization. Therefore, many governments have initiated programs to transition towards significantly more sustainable economies and societies over the next decades, for example Japan's Society 5.0 Agenda (Ferreira \& Serpa, 2018; Seele \& Lock, 2017; Wong, 2013). Above all, the United Nations member states have adopted the 2030 Agenda for Sustainable Development in 2015 with the well-known Sustainable Development Goals (United-Nations, 2015). "The 17 Sustainable Development Goals and 169 targets ... are integrated and indivisible and balance the three dimensions of sustainable development: the economic, social and environmental" (United-Nations, 2015, p. 1).

Specifically, the 2030 Agenda for Sustainable Development lists 17 goals (United-Nations, 2015) in the following shortened version on its website: "no poverty; zero hunger; good health and well-being; quality education; gender equality; clean water and sanitation; affordable and clean energy; decent work and economic growth; industry, innovation and infrastructure; reduced inequalities; sustainable cities and communities; responsible consumption and production; climate action; life below water; life on land; peace, justice and strong institutions; partnerships for the goals" (United-Nations, 2015). In a similar vein, many firms have set up strategic initiatives to increase their sustainability in terms of balancing economic, environmental, and social factors in the triple bottom line (Elkington, 2018). For example, the German automotive supplier Bosch has taken major steps to reduce its environmental footprint, and the company has claimed to make its over 400 locations carbon neutral in 2020 (Bosch, 2020). In particular, many executives now acknowledge the major opportunities for innovation by pursuing sustainability (Lichtenthaler, 2017; Pfitzer, Bockstette, \& Stamp, 2013).

Beyond this renewed interest in sustainability, digitalization has recently been a key topic on the strategic agenda of many firms (Balsmeier \& Woerter, 2019; Berman, 2012). Executives have widely acknowledged the need for transforming their organizations in light of new technological opportunities resulting from a variety of digital solutions, advanced data analytics, and artificial intelligence applications (Boldosova \& Luoto, 2019; Lichtenthaler, 2020b; Loebbecke \& Picot, 2015). Digitalization and artificial intelligence may help companies to optimize their established business processes, but they may also enable firms to create new solutions for their customers and to develop new business fields (Haefner, Wincent, Parida, \& Gassmann, 2021; Huang, Henfridsson, Liu, \& Newell, 2017). Therefore, many firms across the majority of industries have started particular digital transformation initiatives in recent years (Warner \& Wäger, 2019; Westerman \& Bonnet, 2015). The COVID-19 pandemic has speeded up these developments by illustrating the need for proficient digital processes because firms with a higher level of digitalization could usually manage the crisis more productively than their competitors (Shah \& Shah, 2020; Wittbold, Carroll, lansiti, Zhang, \& Landman, 2020).

Thus, the COVID-19 pandemic has further underscored the strategic relevance of digitalization and sustainability. Many firms have actually responded to these developments for many years by initiating proactive and reactive strategic and operational measures (Bradley, 2007; Cokcetin, 2017). So far, however, most of these initiatives have focused on one of the two megatrends, i.e. either sustainability or digitalization (Gupta, Motlagh, \& Rhyner, 2020). In contrast, programs to combine particular topics of sustainability and digitalization have often just been started in recent years, and they still do not constitute the major part of most firms' activities that are related to sustainability and digitalization (Holst, Löffler, \& Philipps, 2017; Osburg, 2017). Nonetheless, there are major opportunities for digital sustainability because digital tools may, for example, play 
a key role in reducing a firm's carbon footprint (Gensch, Prakash, \& Hilbert, 2017; Ordieres-Meré, Remón, \& Rubio, 2020). At the same time, a growing use of digital solutions may also have a negative environmental impact which calls for sustainable digitalization to reduce potential negative consequences (Stuermer, Abu-Tayeh, \& Myrach, 2017; Wenzel, 2017). Apart from some exceptions, however, most companies do not yet proficiently address the interdependencies between sustainability and digitalization (Benetello, 2021; Kiron \& Unruh, 2018).

Similar to the limited attention to combining sustainability and digitalization in practice, prior research has only started to address this topic (Gupta et al., 2020). There is a large body of management research about sustainability and related fields for many decades (O'Connor \& Gronewold, 2013; Schaltegger \& Wagner, 2011), which illustrates potential unintended consequences of strategic initiatives and innovative solutions (Thackara, 2015). In addition, research into managing digitalization has strongly increased in recent years (Dellermann, Fliaster, \& Kolloch, 2017; Svahn, Matthiasen, \& Lindgren, 2017). Despite the high theoretical and managerial relevance, however, the number of works that specifically focus on merging sustainability and digitalization is very limited (Gebhardt, 2017; Linkov, Trump, Poinsatte-Jones, \& Florin, 2018). There are some noteworthy exceptions, including the concept of digitainability, which was recently suggested to indicate the combination of digitalization and sustainability (Gupta et al., 2020), as well as earlier research into sustainable design (Thackara, 2006, 2015). This conceptual article draws on the recent concept of digitainability (Gupta et al., 2020) and on an innovation-based approach (Lichtenthaler, 2016; Rodrigues-Alves, 2018) as well as research into sustainable design (Sherwin, 2004; Thackara, 2015) in order to bridge the gaps in prior research by developing a conceptual framework for combining digitalization and sustainability in the strategic initiatives of companies across various sectors. On this basis, it highlights three key trends how firms may address the combination of these two megatrends.

This conceptual article delivers a few contributions. First, it extends existing work about digitalization (Andriole, 2017; Serban, 2017) by underscoring the need for overcoming potential negative effects of an increased use of digital solutions in order to enable sustainable digital transformation. Second, this article contributes to sustainability research by offering a systematic overview how firms and researchers may explore new digitainability opportunities that result from combining digitalization and sustainability (Gupta et al., 2020; Maier, Maier, Aschilean, Anastasiu, \& Gavris, 2020). Third, this article deepens our knowledge of the innovation-based view (Lichtenthaler, 2016; Rodrigues-Alves, 2018) and sustainable design (Sherwin, 2004; Thackara, $2006,2015)$ by emphasizing the relevance of combining multiple types of innovation in order to achieve growth from sustainability initiatives rather than exclusively focusing on efficiency

benefits. Fourth and finally, this article generates new knowledge for research about strategic renewal (Baumgartner \& Mangematin, 2019; Zahra, Sapienza, \& Davidsson, 2006) because it underscores the relevance of transforming and reconfiguring a firm's innovation processes in light of the long-term impact that the megatrends of digitalization and sustainability along with their interdependencies will have on most firms' business activities.

\section{Sustainability and Digitalization}

The Sustainable Development Goals of the United Nations (United-Nations, 2015) underscore that sustainability constitutes one of the key trends for policymakers, companies as well as individuals. With regard to companies, an innovation-based perspective suggests that sustainability will have a massive impact on the transformation of many industries over the next years and decades (Hoek, 2017; Lichtenthaler, 2016; Sachs, Schmidt-Traub, Mazzucato, Messner, Nakicenovic, \& 
Rockström, 2019). In fact, sustainability will have major consequences for firms in nearly all industries from the energy sector with a focus on renewable energy and the automotive sector with more sustainable mobility to the fashion industry with a more sustainable production of new fashion items. Overall, sustainability is a relatively broad concept, and there are many different conceptual understandings of what it actually comprises (Hahn \& Kühnen, 2013; Maier et al., 2020). Many contributions to the literature argue that sustainability goes beyond conserving the environment and also involves economic and social factors, leading to the triple bottom line of financial, environmental, and social outcomes (Elkington, 2018). This understanding is consistent with the Sustainable Development Goals (United-Nations, 2015) and with the concept of creating shared value, which describes firms' activities of achieving financial and strategic goals while positively contributing to the environment as well as society (Pfitzer et al., 2013; Porter \& Kramer, 2011).

The huge public attention to sustainability in past years and decades may be relatively new, including the United Nations' Sustainable Development Goals (United-Nations, 2015) and Japan's Society 5.0 Agenda (Ferreira \& Serpa, 2018). However, the roots of sustainability can actually be traced back several centuries (Caradonna, 2014). As such, a large body of prior research into sustainability and related topics from various disciplines has developed, including the natural resource-based view (Hart, 1995; Hart \& Dowell, 2011). On this basis, many companies have set up particular initiatives with multiple individual measures in order to enhance the sustainability of their business activities (Artiach, Lee, Nelson, \& Walker, 2010; Montiel \& Delgado-Ceballos, 2014; Reichel \& Seeberg, 2011). In this regard, the management of sustainability in companies has recently been defined by the research and advisory firm Gartner as follows. "Sustainability management ... focuses on products, services, the enterprise and the supply chain, and it seeks to optimally balance organizational performance and outcomes across economic, environment and social criteria over all time scales" (Gartner, 2021).

Moreover, prior research from an innovation-based perspective has emphasized how different types of innovation, such as new products, services, processes, and business models, may positively contribute to the triple bottom line (Fichter \& Clausen, 2016; Lichtenthaler, 2017; Pfitzer et al., 2013). In addition, there is an influential line of arguments about sustainable design, which highlights the role of desired goals rather than unintended consequences of new products, services, processes, and solutions (Sherwin, 2004; Thackara, 2015). In this regard, John Thackara offered some key insights in his 2006 book 'In the bubble - Designing in a complex world' based on a relatively broad understanding of design, which is relevant for designers, executives, policymakers, academics, and basically all of us (Thackara, 2006). For example, the book highlighted the need for examining in detail the long-term consequences of design, innovation, and other activities because this long-term impact had often been neglected in business activities and public discussions (Thackara, 2006). Further works also underscored the relevance of designing sustainable new solutions (Ehrenfeld, 2008; Sherwin, 2004) and attempting to leave better conditions rather than only doing less harm to the environment (Thackara, 2015).

Despite the variety of innovation activities that currently have at least some sustainability focus in many firms, they are usually quite unrelated to digitalization initiatives that the same firms have often established in recent years (del Río Castro et al., 2020; Maier et al., 2020). This relative independence of sustainability and digitalization is surprising, especially since both megatrends call for substantial transformation and change in many companies (Clausen, Göll, \& Tappeser, 2017; George, Merrill, \& Schillebeeckx, 2020; Motwani, 2014; Narayan, 2019). However, the very limited interdependencies of managing sustainability and digitalization at present are also illustrated by many firms' sustainability reports, which usually describe multiple measures to reduce 
resource consumption with a quite exclusive focus on non-digital measures (Hahn \& Kühnen, 2013; Kolk, 2004). Thus, sustainability and digitalization are key items on the strategic agendas of many companies in various sectors. However, the implementation of particular initiatives and measures occurs in relative isolation without considering the potential positive and negative interdependencies (George et al., 2020; Stuermer et al., 2017).

With regard to digitalization, the advisory and research company Gartner has suggested the following definition, which has become relatively popular: "Digitalization is the use of digital technologies to change a business model and provide new revenue and value-producing opportunities; it is the process of moving to a digital business" (Gartner, 2019). This process of moving to a digital business already indicates the major need for transformation that is often required if firms aim at achieving a higher level of digitalization (Lichtenthaler, 2020a; Westerman \& Bonnet, 2015). Because of the new opportunities that it provides, digitalization may also contribute to higher levels of sustainability, which would indicate positive interdependencies among these two megatrends. In fact, digitalization can speed up the evolution towards reducing the carbon footprint, and it helps to connect people worldwide which may encourage a culture of global collaboration and sense of urgency to address environmental concerns (Aksin-Sivrikaya \& Bhattacharya, 2017; Gupta et al., 2020; United-Nations, 2015).

At the same time, there may also be negative interdependencies between digitalization and sustainability. Digitalization may positively contribute to a firm's financial goals, but it may simultaneously have negative environmental effects and may strengthen social divides (AksinSivrikaya \& Bhattacharya, 2017; Gupta et al., 2020; Sachs et al., 2019). For example, merely focusing on analog, non-digital efficiency will not be enough. Rather, companies may also need to address digital efficiency (Lichtenthaler, 2021) to reduce the energy consumption of digital tools, smart devices, video streaming, Internet of Things, and diverse artificial intelligence applications in the context of growing digitalization (Hao, 2019; Huelsenbeck, 2007). Thus, executives may have to transform their organizations to enable a successful co-existence of financial and sustainability goals in an increasingly digital business environment (Alberti \& Varon Garrido, 2017; Motwani, 2014). In this regard, the term digitainability was recently coined, and it "refers to the crossfertilization between the processes of digitalization and sustainable development" (Gupta et al., 2020 , p. 3), which is addressed in more detail in the following.

\section{Towards Digitainability}

In the broader context of the Sustainable Development Goals (United-Nations, 2015), the combination of digitalization and sustainability has only begun to emerge as an important new field of research (Benetello, 2021; Gupta et al., 2020). To complement and extend the limited number of prior works, an innovation-based theoretical perspective (Lichtenthaler, 2016; Rodrigues-Alves, 2018 ) is adopted because its inherently dynamic view fits well with the transformation requirements that often result from digitalization and sustainability - and particularly from their combination. As such, a conceptual framework is developed, which considers digitalization and sustainability as two different dimensions, which are not always completely independent. Rather, companies may pursue either digitalization or sustainability, or they may pursue both or none to a strong degree. This conceptual perspective is helpful because it allows for distinguishing a different strategic emphasis of companies along with a systematic framework for identifying new opportunities. Specifically, four different situations are distinguished according to the level of digitalization and sustainability (Figure 1).

First, the established business activities of firms from many sectors were typically characterized 




Figure 1. Conceptual Framework

by limited levels of digitalization and sustainability (Berman, 2012; Vrbsky, Galloway, Carr, Nori, \& Grubic, 2013). This does not mean that the companies did not acknowledge the relevance of sustainability or digital tools at all. Of course, most companies tried to consider resources efficiently, and they also relied on information technology in the past. However, the core business processes in many companies did not specifically address topics that are now considered as sustainability and digitalization. Accordingly, the business activities in the lower left corner of the matrix primarily focus on financial goals rather than balancing financial, environmental, and social aspects. In addition, the level of digitalization, for example in terms of recent digital solutions or data-based business models, is very limited in these activities. Nonetheless, many of these activities continue to be critical processes for the companies even if their extent is decreasing over time due to the ongoing digitalization and sustainability programs in many firms (del Río Castro et al., 2020; Gebhardt, 2017).

Second, many companies have established typical sustainability initiatives, which are usually characterized by a high level of sustainability and a low level of digitalization (Hahn \& Kühnen, 2013; Kolk, 2004). While some companies have established such initiatives already for a long time along with particular sustainability reports, the importance of these initiatives for the core business has often increased in recent years, and many other companies have just started particular sustainability programs over the past years in response to the Sustainable Development Goals (Hoek, 2017; Maier et al., 2020; Schaltegger \& Wagner, 2011; Thackara, 2015). Some companies pay particular attention to the possibilities for strengthening sustainability with digital solutions, but most sustainability initiatives clearly have a non-digital, analog focus. An example for a sustainability initiative is provided by the Swedish furniture company IKEA, which plans to become a climate positive business by the year 2030 (IKEA, 2020). Furthermore, the company's strategy 
specifically includes the plan to make sustainable products and services affordable to a broad range of customers (IKEA, 2020).

Third, a large number of firms have set up typical digitalization initiatives in recent years, and these programs are usually described by high levels of digitalization and low levels of sustainability (Nylén \& Holmström, 2015; Trueman, 2019). Of course, the companies already used digital solutions and information technologies in the past, but their importance for the core business has often increased dramatically. Specifically, the companies now rely more on the collection, analysis, and utilization of additional data based on new sensors, advanced analytics, smart algorithms, and multiple further applications of artificial intelligence (Krimpmann \& Stühmeier, 2017; Mandal, 2018). For instance, General Electric strongly relies on collaborations among digitalization and artificial intelligence experts with domain experts, for example from engineering and development, in order to achieve benefits from digitalizing its established business activities, and these benefits may involve cost reductions as well as new revenues from innovative products and services (Woyke, 2017). In most companies, these initiatives have strongly focused on digitalization, whereas sustainability has not played a strong role.

Fourth, due to this particular strategic focus, there are new digitainability opportunities in many companies which refer to a major unrealized potential that would result from combining high levels of digitalization with high levels of sustainability (Gupta et al., 2020). Strategic initiatives and operational measures that combine high levels of digitalization and sustainability may provide benefits in terms of efficiency increases as well as new business development and innovation (Bahrami, Atkin, \& Landin, 2019; Benetello, 2021; Bergset \& Fichter, 2015; del Río Castro et al., 2020). For example, the German conglomerate Siemens has developed a cloud-based solution for energy efficiency analytics in order to offer customers an opportunity for integrated big data collection, processing, and analytics (Siemens, 2020). By optimizing energy consumption and decreasing costs based on an intelligent digital solution, its successful implementation is an example for the opportunities from digitainability (Gupta et al., 2020) and sustainable design (Thackara, 2006) because it specifically combines high levels of digitalization and sustainability. As such, it is a major business opportunity for Siemens and further enables its customers to reduce costs while simultaneously increasing the sustainability of their business activities.

Beyond this particular example, there are significant new opportunities for profiting from digitainability in many firms from a variety of sectors. At the same time, many executives have become aware of the potential benefits from combining high levels of digitalization and sustainability (Cokcetin, 2017; Holst et al., 2017). Consequently, many companies advance towards achieving at least some of the benefits of digitainability (Gupta et al., 2020), and three trends (indicated by arrows in Figure 1) are particularly noteworthy in this regard. The first trend refers to exploring digital sustainability. Here, the focus is on sustainability programs, which many companies have established over the past years. In light of the new digital possibilities, the companies now transform, extend, and complement those established sustainability initiatives by means of digital solutions (Gensch et al., 2017; Seele \& Lock, 2017). Consequently, they explore ways to further enhance the impact and strength of their sustainability initiatives beyond the analog, non-digital context by complementing them with specific digital tools that fit well with the particular setting. For example, smart parking includes various technologies, such as mobile applications, parking sensors, and data analytics. By using digital tools, major sustainability benefits may be achieved. "Recent smart parking case studies have shown a 30\% reduction in greenhouse gas emissions in cities, a $10 \%$ reduction in traffic, and an increase of $2 \%$ in local GDP" (Evans, 2017).

The second major trend is related to enabling sustainable digitalization. Here, the focus is 
on digitalization initiatives, which many companies have started in recent years to modernize, to optimize, and to extend their established business activities. Thus, the major attention of these programs has been on the digital transformation of organizations. Beyond a mere side effect, companies now realize the additional benefits for sustainability by adapting and extending these programs (Gensch et al., 2017; Kiron \& Unruh, 2018). At the end of the day, many firms realize the significant potential for sustainability improvements although the initial focus of these programs was on digital transformation. For example, the US retailer Walmart has extended several digital solutions to optimize its supply chain in order to reduce waste and energy usage (ByteAnt, 2020). Thus, the programs for optimizing its business activities have been enriched by additional sustainability benefits.

The third important trend refers to empowering balanced digitainability. In this regard, companies focus neither on digitalization nor on sustainability. Rather, they establish new strategic initiatives that are directed at combining and merging digitalization and sustainability from the beginning (del Río Castro et al., 2020; Gupta et al., 2020). Accordingly, the original idea of starting such programs is to enhance sustainability by relying on particular digital tools and solutions. There are many different fields of technology and application that allow for such balanced digitainability. An important example in this regard is the efficiency of digital tools, which has often been overlooked so far (Sweney, 2020; Vrbsky et al., 2013). By ensuring high levels of efficiency in this digital context, companies may simultaneously contribute to financial, environmental, and social goals (Lichtenthaler, 2021). For instance, the immense energy consumption of data management centers is largely overlooked (Trueman, 2019). At least, Google's DeepMind artificial intelligence and especially its machine learning capabilities, have contributed to reducing the energy that is required for cooling by up to 40 percent (Evans \& Gao, 2016). As such, this combination of artificial intelligence with several other digital solutions for sustainability purposes is an example of sustainable design (Thackara, 2015) and digitainability (Gupta et al., 2020).

\section{Discussion}

The new conceptual arguments along with the examples for digital sustainability, sustainable digitalization, and digitainability have several consequences for research, practice, and policy in different fields. First, the framework goes beyond prior work about digitalization (Andriole, 2017; Hänninena et al., 2020) by highlighting that the focus of most firms' digitalization initiatives as well as public policy programs about digitalization in recent years have been relatively independent from sustainability initiatives. Thus, potential positive consequences of these digitalization programs on sustainability rather constitute side effects without being at the core attention of executives and policymakers. In addition, this focus of most firms' digitalization initiatives underscores a potential dark side of digitalization due to an increasing carbon footprint and energy consumption based on a multitude of additional sensors, artificial intelligence applications, and further digital tools (Trueman, 2019; Vrbsky et al., 2013). From a sustainability perspective, there is a need for overcoming these potential negative effects of an increased use of digital solutions in order to have a positive net effect and to enable sustainable digital transformation.

Second, the conceptual framework provides new insights for sustainability research and policy (del Río Castro et al., 2020; Maier et al., 2020; United-Nations, 2015). In the context of the Sustainable Development Goals (Hoek, 2017; United-Nations, 2015), the conceptual framework offers a systematic overview how organizations may extend their current sustainability initiatives and explore new opportunities. There may be substantial opportunities that would stem from combining sustainability with digitalization according to the notion of digitainability (Gupta et al., 
2020). These opportunities have often been neglected, and it is time to leverage the interfaces of digitalization and sustainability initiatives. Sustainability programs increasingly become a core activity of many companies, and this is also true for digital transformation initiatives. Of course, there will also be several fields in the future where only digitalization or sustainability continue to be relevant. Nonetheless, there will be a growing intersection of topics in terms of digitainability (Gupta et al., 2020), and they will affect the mainstream business activities. Companies should actively address these new opportunities, which may provide the basis for developing new core competencies for an increasingly digital and sustainability-driven competitive environment in the future.

Third, the conceptual arguments and examples have underscored the relevance of the innovationbased view (Lichtenthaler, 2016; Rodrigues-Alves, 2018) and sustainable design concepts (Ehrenfeld, 2008; Thackara, 2006, 2015) with regard to strategy and policy in the context of digitalization and sustainability. The arguments and examples have highlighted the benefits of combining different types of innovation, such as product, business model, service, and process innovation (Guimaraes, Severo, Campos, El-Aouar, \& Azevedo, 2020; Lichtenthaler, 2017; Pfitzer et al., 2013). Firms may achieve the goals of their sustainability initiatives, and they may further strengthen their existing and new business activities. Consequently, companies may be able to generate additional growth from sustainability programs rather than exclusively aiming at efficiency benefits, for example in terms of reducing the consumption of energy and other resources (Lichtenthaler, 2021). At the same time, companies design new solutions for the entire planet rather than for specific consumers only by taking into account the potential unintended consequences in the long run (Ehrenfeld, 2008; Thackara, 2006). Thus, executives, policymakers, and individuals may focus their attention on leaving better conditions rather than doing less harm (Thackara, 2015). As such, the innovation-based view further supports the perspective of linking sustainability initiatives to a firm's established core business beyond optimization programs and simultaneous resource and cost savings. Instead, there may be major growth opportunities from combining different types of innovation to address digitainability solutions (del Río Castro et al., 2020; Gupta et al., 2020).

Fourth and finally, the conceptual framework provides new insights into strategic renewal research in the post-COVID-19 era (Reeves et al., 2020; Zahra et al., 2006). In the literature, there is relative agreement that the two megatrends of digitalization and sustainability will continue to have a substantial long-term impact on companies in most sectors (Gupta et al., 2020; Richter, Kraus, Brem, Durst, \& Giselbrecht, 2017; Sachs et al., 2019). The particular focus of these megatrends may change over time. For instance, after an initial focus of digitalization initiatives on basic data analytics applications, companies in many industries now increasingly exploit more advanced algorithms based on artificial intelligence (Krimpmann \& Stühmeier, 2017; Lichtenthaler, 2020a). In a similar vein, the specific emphasis of sustainability in a particular industry may change over time. However, the general relevance of these two megatrends will continue, and the importance of their interdependencies in terms of digitainability only begins to unfold (Benetello, 2021; Gupta et al., 2020). Thus, companies need to prepare for dynamically transforming and reconfiguring their innovation processes to profit from the long-term impact that these interdependencies will most likely have on their business activities.

\section{Conclusion, limitations, and outlook}

The concept of digitainability, which has recently been suggested (Gupta et al., 2020), is very promising because it underscores the importance of potential cross-fertilization effects between digitalization and sustainability, which have often been neglected so far. In the context of the 
Sustainable Development Goals (United-Nations, 2015), this article goes beyond the initial works about digitainability (Benetello, 2021; Gupta et al., 2020; Kiron \& Unruh, 2018) to arrive at a conceptual framework, which distinguishes several situations referring to whether firms pursue either digitalization or sustainability - or both or none of them to a strong degree. As such, this article builds on earlier work into sustainable design and related fields (Sherwin, 2004; Thackara, 2006, 2015) to offer a systematic overview of the either independent or interdependent relevance of these two megatrends for companies. Over the next years, the stand-alone importance of digitalization and sustainability will likely continue to grow. Even if digitalization constitutes a key item on many firms' strategic agendas for several years, many companies are still at the beginning of their transformation processes. Beyond the individual importance of the two megatrends, their interaction will most probably gain further importance.

Drawing on existing concepts from the literature, such as the digitainability concept (Gupta et al., 2020), the shared value creation framework (Porter \& Kramer, 2011), the innovation-based view (Lichtenthaler, 2016), and sustainable design (Thackara, 2006), this article focuses the awareness of researchers, policymakers, and executives on the potential positive and negative interdependencies between digitalization and sustainability (del Río Castro et al., 2020; Kiron \& Unruh, 2018). Due to its purely conceptual nature, this article has several limitations and may only serve as a starting point for further research, especially empirical work. For example, in-depth case studies exploring particular digitainability applications appear to be highly promising. In addition, surveys of digitalization and sustainability experts as well as systematic analyses of corporate sustainability reports with regard to digitalization topics may offer essential new insights.

The current and future practices and approaches of addressing sustainability in a digital innovation context deserve particular attention. Specifically, trend impact analyses, the exploration of coherent measures for digitainability as well as a more detailed explanation and visualization of the interdependencies between digitalization and sustainability appear to be highly promising areas for future studies. A deeper understanding of the potential positive and negative interdependencies between digitalization and sustainability is equally important for policymakers, academics, and practitioners in the context of the Sustainable Development Goals (United-Nations, 2015). In particular, digitainability offers the opportunity to move beyond optimization and cost savings due to digitalization and sustainability initiatives in order to capture the cross-fertilization potential of these two megatrends for innovation and new business development.

\section{References}

Aksin-Sivrikaya, S., \& Bhattacharya, C. B. 2017. Where Digitalization Meets Sustainability: Opportunities and Challenges. In T. Osburg \& C. Lohrmann (Eds.), Sustainability in a Digital World: New Opportunities Through New Technologies: 37-49. Berlin: Springer.

Alberti, F. G., \& Varon Garrido, M. A. 2017. Can profit and sustainability goals co-exist? New business models for hybrid firms. Journal of Business Strategy, 38(1): 3-13.

Andriole, S. J. 2017. Five myths about digital transformation. MIT Sloan Management Review, 58(3): 20-22.

Artiach, T., Lee, D., Nelson, D., \& Walker, J. 2010. The determinants of corporate sustainability performance. Accounting and Finance, 50(1): 31-51.

Bahrami, S., Atkin, B., \& Landin, A. 2019. Enabling the diffusion of sustainable product innovations in BIM library platforms. Journal of Innovation Management, 7(4): 106-130. 
Balsmeier, B., \& Woerter, M. 2019. Is this time different? How digitalization influences job creation and destruction. Research Policy, 48(8).

Baumgartner, M., \& Mangematin, V. 2019. Strategy renewal: Breaking the mould with new business models. Journal of Business Strategy, 40(2): 22-31.

Benetello, R. 2021. MySay: Digitainability - combining digitalisation and sustainability. The Edge Malaysia. Accessed on 9th July 2021: https://www.theedgemarkets.com/article/mysay-digitainability- \% E2\%80\%94-combining-digitalisation-and-sustainability.

Bergset, L., \& Fichter, K. 2015. Green start-ups - a new typology for sustainable entrepreneurship and innovation research. Journal of Innovation Management, 3(3): 118-144.

Berman, S. J. 2012. Digital transformation: opportunities to create new business models. Strategy \& Leadership, 40(2): 16-24.

Boldosova, V., \& Luoto, S. 2019. Storytelling, business analytics and big data interpretation: Literature review and theoretical propositions. Management Research Review, 43(2): 204-222.

Bosch. 2020. Carbon neutrality by 2020. Stuttgart. Accessed on 9th July 2021: https: //www.bosch.com/company/sustainability/environment/.

Bradley, K. 2007. Defining digital sustainability. Library Trends, 56(1): 148-163.

ByteAnt. 2020. Sustainability Technology: The Best Examples of Implementation. ByteAnt Blog. Accessed on 9th July 2021: https://www.byteant.com/blog/5-great-examples-of-sustainable-technology-implem

Caradonna, J. L. 2014. Sustainability: A History. Oxford: Oxford University Press.

Carlsson-Szlezak, P., Reeves, M., \& Swartz, P. 2020. Understanding the economic shock of coronavirus. Harvard Business Review Digital Articles, https://hbr.org/2020/03/understandingthe-economic-shock-of-coronavirus.

Clausen, J., Göll, E., \& Tappeser, V. 2017. Sticky Transformation: How path dependencies in socio-technical regimes are impeding the transformation to a Green Economy. Journal of Innovation Management, 5(2): 111-138.

Cokcetin, G. 2017. Digital Sustainability in the Banking and Finance Sector. In T. Osburg \& C. Lohrmann (Eds.), Sustainability in a Digital World: New Opportunities Through New Technologies: 181-187. Berlin: Springer.

del Río Castro, G., González-Fernández, M. C., \& Uruburu-Colsa, A. 2020. Unleashing the convergence amid digitalization and sustainability towards pursuing the Sustainable Development Goals (SDGs): A holistic review. Journal of Cleaner Production, 280: 122204.

Dellermann, D., Fliaster, A., \& Kolloch, M. 2017. Innovation risk in digital business models: the German energy sector. Journal of Business Strategy, 38(5): 35-43.

Ehrenfeld, J. R. 2008. Sustainability by Design. New Haven: Yale University Press.

Elkington, J. 2018. 25 Years Ago I Coined the Phrase "Triple Bottom Line." Here's Why It's Time to Rethink It. Harvard Business Review Digital Articles.

European-Commission. 2020. Recovery plan for Europe. Strategy. Accessed on 9th July 2021: https://ec.europa.eu/info/strategy/recovery-plan-europe_en.

Evans, N. D. 2017. Digital sustainability: Digital transformation's next big opportunity. CIO, Accessed on 9th July 2021: https://www.cio.com/article/3170647/digital-sustainability-digital- 
transformations-next-big-opportunity.html.

Evans, R., \& Gao, J. 2016. DeepMind Al Reduces Google Data Centre Cooling Bill by 40\%. DeepMind Blog. Accessed on 9th July 2021: https://deepmind.com/blog/article/deepmind-ai-reduces-google-data-c

Ferreira, C. M., \& Serpa, S. 2018. Society 5.0 and social development. Management and Organizational Studies, 5: 26-31.

Fichter, K., \& Clausen, J. 2016. Diffusion Dynamics of Sustainable Innovation - Insights on Diffusion Patterns Based on the Analysis of 100 Sustainable Product and Service Innovations. Journal of Innovation Management, 4(2): 30-67.

Fowler, S. J., \& Hope, C. 2007. Incorporating Sustainable Business Practices into Company Strategy. Business Strategy and the Environment, 16: 26-38.

Gartner. 2019. Digitalization. Information technology glossary. Accessed on 9th July 2021: https://www.gartner.com/en/information-technology/glossary/digitalization.

Gartner. 2021. Sustainability management. Information technology glossary. Accessed on 9th July 2021: https://www.gartner.com/en/information-technology/glossary/sustainability-management.

Gebhardt, C. 2017. Humans in the Loop: The Clash of Concepts in Digital Sustainability in Smart Cities. In T. Osburg \& C. Lohrmann (Eds.), Sustainability in a Digital World: New Opportunities Through New Technologies: 85-94. Berlin: Springer.

Gensch, C.-O., Prakash, S., \& Hilbert, I. 2017. Is Digitalisation a Driver for Sustainability? In T. Osburg \& C. Lohrmann (Eds.), Sustainability in a Digital World: New Opportunities Through New Technologies: 117-129. Berlin: Springer.

George, G., Merrill, R. K., \& Schillebeeckx, S.J.D. 2020. Digital Sustainability and Entrepreneurship: How Digital Innovations Are Helping Tackle Climate Change and Sustainable Development. Entrepreneurship Theory \& Practice.

Guimaraes, J.C.F. de, Severo, E. A., Campos, D. F., El-Aouar, W. A., \& Azevedo, F.L.B.d. 2020. Strategic drivers for product and process innovation: A survey in industrial manufacturing, commerce and services. Benchmarking: An International Journal, 27(3): 1159-1187.

Gupta, S., Motlagh, M., \& Rhyner, J. 2020. The Digitalization Sustainability Matrix: A Participatory Research Tool for Investigating Digitainability. Sustainability, 12: 1-27.

Haefner, N., Wincent, J., Parida, V., \& Gassmann, O. 2021. Artificial intelligence and innovation management: A review, framework, and research agenda. Technological Forecasting and Social Change, 162: 120392.

Hahn, R., \& Kühnen, M. 2013. Determinants of sustainability reporting: a review of results, trends, theory, and opportunities in an expanding field of research. Journal of Cleaner Production, 59: 5-21.

Hänninena, L. I., Byrgeb, C., Núnez-Gómeza, P., Tangc, C., Brondumb, K., Dinglid, S. M., \& Xerxend, S. P. 2020. Testing the Effects of Digital Gamified Creativity Training. Journal of Creativity and Business Innovation, 6: 5-17.

Hao, K. 2019. Training a single Al model can emit as much carbon as five cars in their lifetimes. MIT Technology Review, Accessed on 9th July 2021: https://www.technologyreview.com/2019/ 06/06/239031/training-a-single-ai-model-can-emit-as-much-carbon-as-five-cars-in-their-lifetimes/.

Hart, S. L. 1995. A natural-resource-based view of the firm. Academy of Management Review, 
20(4): 986-1014.

Hart, S. L., \& Dowell, G. 2011. A Natural-Resource-Based View of the Firm: Fifteen Years After. Journal of Management, 37(5): 1464-1479.

Hoek, M. 2017. CSV and the SDGs - Creating Shared Value Meets the Sustainable Development Goals. Huffpost. Accessed on 9th July 2021:: https://www.huffpost.com/entry/ csv-and-the-sdgs-creating-shared-value-meets-the_b_58eb9ceae4b0acd784ca5a63? guccounter= 1.

Holst, A., Löffler, C. R., \& Philipps, S. 2017. How Digital Reframes the Business Case for Sustainability in Consumer Markets. In T. Osburg \& C. Lohrmann (Eds.), Sustainability in a Digital World: New Opportunities Through New Technologies: 105-116. Berlin: Springer.

Huang, J., Henfridsson, O., Liu, M. J., \& Newell, S. 2017. Growing on Steroids: Rapidly Scaling the User Base of Digital Ventures Through Digital Innovation. MIS Quarterly, 41(1): 301-314.

Huelsenbeck, C. 2007. Next-Gen Data Management. Pollution Engineering, 39(1): 32-35.

IKEA. 2020. Highlights from the IKEA Sustainability report FY20. Sustainability.Accessed on 9th July 2021: https://about.ikea.com/en/sustainability/sustainability-report-fy20.

Keller, W., \& Bette, N. 2020. Shaping digital sustainable development in chemical companies. Journal of Business Chemistry, 2: 9-18.

Kiron, D., \& Unruh, G. 2018. The Convergence of Digitalization and Sustainability. MIT Sloan Management Review, Accessed on 9th July 2021: https://sloanreview.mit.edu/article/ the-convergence-of-digitalization-and-sustainability/.

Kolk, A. 2004. A decade of sustainability reporting: developments and significance. International Journal of Environment and Sustainable Development, 3(1): 51-64.

Krimpmann, D., \& Stühmeier, A. 2017. Big Data and Analytics: Why an IT Organization Requires Dedicated Roles to Drive Sustainable Competitive Advantage. International Journal of Service Science, Management, Engineering and Technology, 8(3): 79-92.

Lichtenthaler, U. 2016. Toward an innovation-based perspective on company performance. Management Decision, 54: 66-87.

Lichtenthaler, U. 2017. Shared Value Innovation: Linking Competitiveness and Societal Goals in the Context of Digital Transformation. International Journal of Innovation and Technology Management, 14: 1-14.

Lichtenthaler, U. 2020a. Building blocks of successful digital transformation: Complementing technology and market issues. International Journal of Innovation and Technology Management, (1): 2050004.

Lichtenthaler, U. 2020b. Integrated intelligence: Combining human and artificial intelligence for competitive advantage. Frankfurt: Campus.

Lichtenthaler, U. 2021. Data management efficiency: Major opportunities for shared value innovation. Management Research Review, in press.

Linkov, I., Trump, B. D., Poinsatte-Jones, K., \& Florin, M.-V. 2018. Governance Strategies for a Sustainable Digital World. Sustainability, 10: 1-8.

Loebbecke, C., \& Picot, A. 2015. Reflections on societal and business model transformation arising 
from digitization and big data analytics: A research agenda. Journal of Strategic Information Systems, 24: 149-157.

Lohrmann, C. 2017. Leadership in a Digital World: New Ways of Leadership for Sustainable Development. In T. Osburg \& C. Lohrmann (Eds.), Sustainability in a Digital World: New Opportunities Through New Technologies: 51-58. Berlin: Springer.

Maier, D., Maier, A., Aschilean, I., Anastasiu, L., \& Gavris, O. 2020. The Relationship between Innovation and Sustainability: A Bibliometric Review of the Literature. Sustainability, 12: 1-20.

Mandal, S. 2018. An examination of the importance of big data analytics in supply chain agility development: A dynamic capability perspective. Management Research Review, 41(10): 1201-1219.

Mention, A.-L., Torkkeli, M., \& Pinto-Ferreira, J. J. 2020. The Era of Digital Enablement: A Blessing or a Curse? Journal of Innovation Management, 8(3): 1-5.

Montiel, I., \& Delgado-Ceballos, J. 2014. Defining and Measuring Corporate Sustainability: Are We There Yet? Organization \& Environment, 27: 113-139.

Motwani, S. 2014. Managing Data Efficiency in Data Centers. Voice \& Data, 21(2): 28-30.

Mühlbacher, H., \& Böbel, I. 2019. From zero-sum to win-win - Organisational conditions for successful shared value strategy implementation. European Management Journal, 37(3): 313-324.

Narayan, R. 2019. Picturing Future Imaginaries for Innovations Towards Sustainability Transitions. Journal of Innovation Management, 7(3): 10-14.

Nylén, D., \& Holmström, J. 2015. Digital innovation strategy: A framework for diagnosing and improving digital product and service innovation. Business Horizons, 58(1): 57-67.

O'Connor, A., \& Gronewold, K. L. 2013. Black Gold, Green Earth: An Analysis of the Petroleum Industry's CSR Environmental Sustainability Discourse. Management Communication Quarterly, 27: $210-236$.

Ordieres-Meré, J., Remón, T. P., \& Rubio, J. 2020. Digitalization: An Opportunity for Contributing to Sustainability From Knowledge Creation. Sustainability, 12: 1-21.

Osburg, T. 2017. Sustainability in a Digital World Needs Trust. In T. Osburg \& C. Lohrmann (Eds.), Sustainability in a Digital World: New Opportunities Through New Technologies: 3-19. Berlin: Springer.

Pfitzer, M., Bockstette, V., \& Stamp, M. 2013. Innovating for Shared Value. Harvard Business Review, 91: 100-107.

Porter, M. E., \& Kramer, M. R. 2011. Creating shared value. Harvard Business Review, 89: $62-77$.

Reeves, M., Lang, N., \& Carlsson-Szlezak, P. 2020. Lead your business through the coronavirus crisis. Harvard Business Review Digital Articles, https://hbr.org/2020/02/lead-your-businessthrough-the-coronavirus-crisis.

Reichel, A., \& Seeberg, B. 2011. The Ecological Allowance of Enterprise: An Absolute Measure of Corporate Environmental Performance, its Implications for Strategy, and a Small Case. Journal of Environmental Sustainability, 1(1): 1-14.

Richter, C., Kraus, S., Brem, A., Durst, S., \& Giselbrecht, C. 2017. Digital entrepreneurship: 
Innovative business models for the sharing economy. Creativity and Innovation Management, 26: 300-310.

Rodrigues-Alves, M. F. 2018. Literature on organizational innovation: past and future. Innovation \& Management Review, 15(1): 2-19.

Sachs, J. D., Schmidt-Traub, G., Mazzucato, M., Messner, D., Nakicenovic, N., \& Rockström, J. 2019. Six Transformations to achieve the Sustainable Development Goals. Nature Sustainability, 2(9): 805-814.

Schaltegger, S., \& Wagner, M. 2011. Sustainable entrepreneurship and sustainability innovation: Categories and interactions. Business Strategy and the Environment, 20: 222-237.

Seele, P., \& Lock, I. 2017. The game-changing potential of digitalization for sustainability: possibilities, perils, and pathways. Sustainability Science, 12: 183-185.

Serban, R.-A. 2017. The impact of big data, sustainability, and digitalization on company performance. Studies in Business and Economics, 12(3): 181-189.

Shah, J., \& Shah, N. 2020. Fighting Coronavirus with Big Data. Harvard Business Review Digital Articles, https://hbr.org/2020/04/fighting-coronavirus-with-big-data.

Sherwin, D. 2004. Design and sustainability. Journal of Sustainable Product Design, 4(1): 21-31.

Siemens. 2020. Optimizing energy and operational costs with analytics and Al. Erlangen, Accessed on 9th July 2021: https://assets.new.siemens.com/siemens/assets/api/uuid:eb9d759b-ab2c-4fa1-a4f0-236c2c7 emdg-t90067-00-7600-white-paper-brochure-300. pdf.

Stuermer, M., Abu-Tayeh, G., \& Myrach, T. 2017. Digital sustainability: basic conditions for sustainable digital artifacts and their ecosystems. Sustainability Science, 12: 247-262.

Svahn, F., Matthiasen, L., \& Lindgren, R. 2017. Embracing Digital Innovation in Incumbent Firms: How Volvo Cars Managed Competing Concerns. MIS Quarterly, 41(1): 239-253.

Sweney, M. 2020. Netflix to slow Europe transmissions to avoid broadband overload. The Guardian: https://www.theguardian.com/media/2020/mar/19/netflix-to-slow-europe-transmissions-to-avoidbroadband-overload.

Thackara, J. 2006. In the bubble: Designing in a complex world. Cambridge: MIT Press.

Thackara, J. 2015. How to thrive in the next economy. London: Thames \& Hudson.

Trueman, C. 2019. Why data centres are the new frontier in the fight against climate change. Computerworld: https://www.computerworld.com/article/3431148/why-data-centres-are-the-newfrontier-in-the-fight-against-climate-change.html.

United-Nations. 2015. Transforming our world: The 2030 agenda for sustainable development. New York: General Assembly.

Vrbsky, S. V., Galloway, M., Carr, R., Nori, R., \& Grubic, D. 2013. Decreasing power consumption with energy efficient data aware strategies. Future Generation Computer Systems, 29(5): 1152-1163.

Warner, K.S.R., \& Wäger, M. 2019. Building dynamic capabilities for digital transformation: An ongoing process of strategic renewal. Long Range Planning, 52(3): 326-349.

Wenzel, F. 2017. Sustainable Digital Business: Crucial Success Factor for Small and Medium-Sized Enterprises and Start-Ups. In T. Osburg \& C. Lohrmann (Eds.), Sustainability in a Digital 
World: New Opportunities Through New Technologies: 131-143. Berlin: Springer.

Westerman, G., \& Bonnet, D. 2015. Revamping your business through digital transformation. MIT Sloan Management Review, 56: 10-13.

Wittbold, K. A., Carroll, C., lansiti, M., Zhang, H. M., \& Landman, A. B. 2020. How Hospitals Are Using Al to Battle Covid-19. Harvard Business Review Digital Articles, https://hbr.org/2020/ 04/how-hospitals-are-using-ai-to-battle-covid-19.

Wong, S.K.S. 2013. Environmental Requirements, Knowledge Sharing and Green Innovation: Empirical Evidence from the Electronics Industry in China. Business Strategy and the Environment, 22: 321-338.

Woyke, E. 2017. General Electric builds an Al workforce. MIT Technology Review, Online: 1-3.

Zahra, S. A., Sapienza, H. J., \& Davidsson, P. 2006. Entrepreneurship and Dynamic Capabilities: A Review, Model and Research Agenda. Journal of Management Studies, 43: 917-955. 


\section{Biographies}

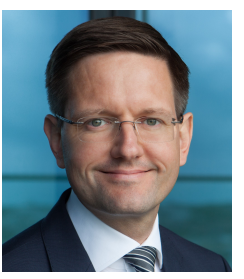

Ulrich Lichtenthaler. Ulrich Lichtenthaler is a Professor of Management and Entrepreneurship at International School of Management (ISM) in Cologne, Germany. He holds a Ph.D. degree in technology management and further is an executive consultant, who has successfully completed over 20 digital transformation and Al projects in recent years. He has taught executive education courses at leading business schools, and he has written multiple books and articles for journals and newspapers, such as Journal of Innovation Management, MIT Sloan Management Review, and Wall Street Journal. He further is author of the recent book 'Integrated Intelligence: Combining Human and Artificial Intelligence for Competitive Advantage'.

CRediT Statement: Sole contributor. 